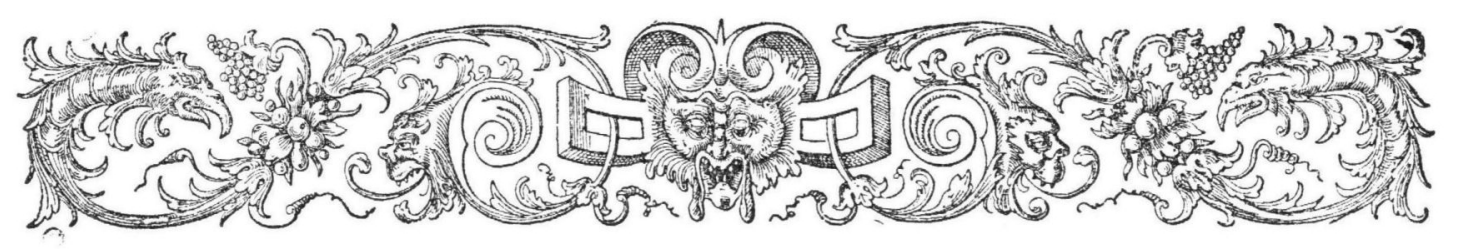

\title{
KRITISCHE OPMERKINGEN OMTRENT OUD-HOLLANDSCHE SCHILDERIJEN IN ONZE MUSEA ${ }^{1}$ )
}

DOOR

\author{
DR. C. HOFSTEDE DE GROOT.
}

IV.

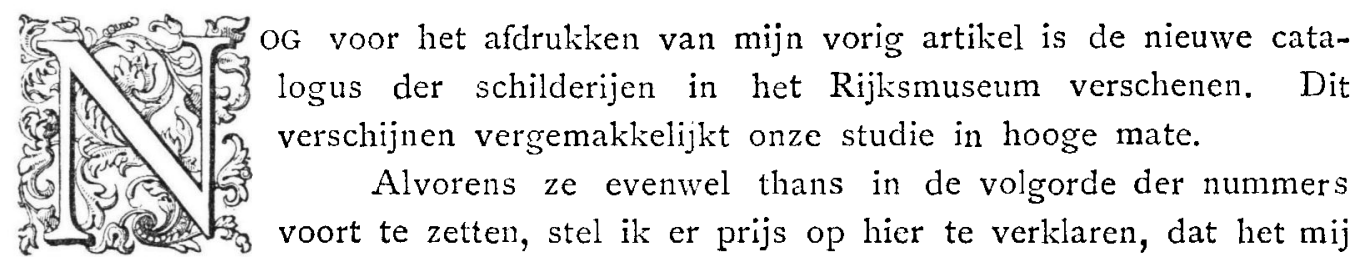
na het verschijnen van het vorig artikel gebleken is, dat BREDIUS, sinds ook hij het portret van den zoogenaamden Menasseh ben Israel door G. FLINCK in de verzameling DE JONG te Parijs kent, het geheei en al met mij eens is, dat de Gozen Centen uit het Rijpenhofje van Flinck en niet van Rembrandt is.

"Nr. 21. Anonymus der Duitsche school, a. XVIe Eeuw (eerste helft), Een Jonkman met baret en pelsmantel. Door Dr. A. BREDIUs aangeduid als werk van den Meister des Todes Mariae (JoOst vaN CLEeF)."

Of BREDIUs de eerste gcweest is, die dit portret aldus heeft aangeduid, waag ik niet te beslissen. ${ }^{2}$ ) De aanduiding schijnt mij evenwel zóó juist, dat zij veilig door den catalogus had kunnen worden overgenomen. Het is mij althans onbekend, dat er onder hen, die zich speciaal met de studie van deze school en

1) Zie Oud-Holland 1889 DI. XVII, blz. I63 en verv.; Igor Dl. XIX, blz. I2I en verv. en blz. I34 en verv.; 1904 Dl. XXII, blz. 27 en verv.

2) Het was BODF meenen wij, die het eerst die toeschrijving maalite. (DE REDACTIE.) 
van dit tijdvak bezig houden, kenners zijn, die aan de juistheid der aanduiding twijfelen.

„No. I I6, Anonymus der Hollandsche School; B. Diyersen. e. XVIIe Eeuw (tweede helft). Omstreeks 1650, Zeegezicht" enz.

De vroegere catalogi vermeldden reeds dat dit schilderij waarschijnlijk het werk is van Willem vaN DIEST (Nr. 589). Het komt mij voor, dat deze toeschrijving zooveel voor zich heeft, dat men het stuk veilig onder WiLLEM VAN DIEST (toegeschreven) kan registreeren.

Twee nummers verder staat onder dezelfde rubriek: No. I I8, Hollandsche schepen nabij het strand. Dit stuk vertoont cen groote naamteekening, die de vorige catalogi lazen als P. Druyve... I689. Het facsimile in den nieuwen catalogus leert, dat de schilder heet J. DE GRSYTER, hetgeen vooral blijkt, indien men de handteekening legt naast die van een schilderij, dat in Igoo door Baron WRANGel te Dresden op de Marinetentoonstelling in den Haag wasingezonden (buiten catalogus) en van een ander, dat den 22 Juni Igor als Nr. I I van een anonyme veiling bij Christie's voorkwam.

Deze JACOB DE GruYTer was een Rotterdamsche schilder, die in 1674 in het kohier van het familiegeld aldaar vocrkomt (Rott. Hist. Bladen III, I, 604) ${ }^{1}$ ). Ook is zijn even vermelde schilderij in de Londensche veiling een Gezicht op Rotterdam, met rechts op den voorgrond een talrijke kudde koeien en schapen en daarachter de stad. Links verscheiden oorlogsschepen en kleinere vaartuigen. Rechts beneden de volle handteekening en het jaar I655;0.70 bij I.05 M. De warme toon met veel gecl en rood verried sterken invloed van CuYP, maar het stuk was helaas zoo zwaar gepoetst, dat het reddeloos verloren was.

Tot een geheel andere richting behoorde het schilderij van Baron WRANGEL, dat een feit uit den Deensch-Zweedschen oorlog heette voor te stellen, maar in werkelijkheid het landen der Hollanders in het fort Sheerness gedurende den tocht naar Chattam afbeeldde. Het was geheel en al gevolgd naar de daarvan bestaande prent van RoMEyn DE Hooghe (Mul.ter, Hist. Pr. No. 2256a onderste helft) vooral wat de aardige figuurtjes aangaat. Ook de gebouwen waren dezelfde, maar anders van afmeting. De voornaamste tinten waren rood in de baksteenen gebouwen en blauwachtig rose in de bergen en de lucht. De artistieke kwaliteit was veel hooger dan die van het vorige schilderij, waarschijnlijk omdat de schilder naar een goed voorbeeld kon werken. Behalve de volle handteekening droeg het het jaartal $1670 .{ }^{2}$ )

1) $\mathrm{Op}_{\mathrm{p}}$ blz. 605 aldaar word in de jaren 1674 en 1632 ook nog een Gerrit de Gruyter vermeld.

2) Intusschen kwam het aI Septembor j.l. in de veiling VAX DER BURGr, DE LA CotrT e.a. voor onder No. 83. Het werd voor $f 250$. - verkocht. De catalogus dateert het stuk ten onrechte 1668 . 
Het vierde schilderij, dat mij van JACOB DE GRUYTER bekend geworden is, bevindt zich in de rijke verzameling Delarof te St. Petersburg. Het is evenwel het zwakste van allen. Het is een Hollandsch zeegevecht bij een rotsachtige kust, dat op den eersten blik den indruk van een J. BEERSTRATEN maakt. In het midden bevindt zich een ronde toren en daarbij op een muur de volle handteekening en het jaartal 1663.

Eindelijk kwam in de veiling van 13 Juli 18 I 2 te Amsterdam nog voor:

No. 46. Een oorlogsvloot. Op paneel, door J. D. Gruiters, hoog 35, breed 60 duim, verkocht voor 5 gld. 5 st.

Anonymi der Hollandsche School, B. Diversen, f, XVIIIe eeuw.

No. 120. Bloemstuk met een valsche handteekening van R. RuYs en het (onmogelijke) jaartal 1659. Heette vroeger RACHeL RuYsch, doch is een copie naar haar en behoort op een zolder, niet in een museumzaal thuis.

No, I 2 I. Stilleven. Schijnt mij een modern schilderij, doch hangt iets te hoog voor nauwkeurig onderzoek.

Anonymus der Hollandsche School, D. Portretten, d. XVIIe Eeuw (eerste helft).

No. 234. Jacoba Bontemantel, als kind ten voeten uit. Anno I644.

Dit schilderij is, evenals zoovele andere familieportretten der VAN DE POLL's, een copie naar een origineel, dat waarschijnlijk bij een anderen staak der familie berust of berust heeft. De gladde schilderwijzc op doek verraadt den lateren oorsprong. Het wil mij voorkomen, dat het origineel wel een vroege AELBERT Cuyp zou kunnen geweest zijn. In de veiling Lenglart, Parijs Igo2, was althans een voluit gemerkt kinderportretje uit het Dordtsche geslacht VAN DER BURCH, waarmede dit zeer veel overeenkomst vertoont. Men vergelijke de af beelding in SEDELMEyers achtsten catalogus onder No. 3.

No. 386, JAN VAN ASSEN, Mansportret, gemonogrammeerd. Wat zijn de redenen, waarom het monoyram J. v. A. JAN VAN ASSEN moet beteekenen? Het schilderij past noch bij hetgeen KRAMM over een voluit gemerkt, levensgroot portret bij de familie HuydeCOPER VAN NigTEveGT mededeelt, noch bij hetgeen HoUBRAKEN over des schilders kunst geboekstaafd heeft.

Evencens zou ik willen vragen, waaruit blijkt dat J. AtTAMA, de schilder van het mansportret No. 388, waarschijnlijk tc Leeuwarden werkte? Zeker werkte hij te Groningen, waar hij tusschen Pinksteren en Vrijmarkt 1659 in het register van het Klein-burgerrecht werd ingeschreven.

No. 433, Portret van cen Mevrouw Kettingh geb. Speyaert, heet het werk van Willem BARTsius. Deze toeschrijving is mij geheel onverklaarbaar, omdat het stuk met reusachtige letters, die ook in den catalogus zijn gefacsimileerd, de handteekening draagt van eenen schilder

$$
\text { Barth (= BARTHOLOMEUS) S... }
$$


Hoe nu Baktholomeus, Willem en S..., Bartsius kan beteekenen, ben ik buiten machte te begrijpen. Ook heeft het stuk niet de minste overeenkomst van stijl met de authentieke werken van BARTSIUS en was deze toen het portret, dat een geoefende schildershand verraadt, in 1630 geschilderd. werd, eerst omstreeks I7 à i 8 jaar oud.

De schilderijen Nrs. 449 en 450 staan op naam van, - No. 45 I wordt door A. Bredius toegeschreven aan Anthonie BeErstraten. Hierbij is eene verwisseling in het spel van Anthonie en Abraham Beerstraten. Men weet, dat er een tijdlang twijfel geheerscht heeft, of er naast $I=$ JoHANnES BEERSTRATEN wel een A. Beerstraten bestaan heeft ${ }^{1}$ ). Deze twijfel hield op, toen in 1886 op de veiling Snouck van Loosen te Enkhuizen een deugdelijk gemerkt schilderij van A... BeERStRATEN voor den dag kwam. De naamteekening luidde niet slechts A., maar voluit Anthonie. Sinds dien heeten alle A. BeErstraten gemerkte stukken het werk van dezen ANTHONIE, waarbij men over 't hoofd zag, welk een enorm verschil van artistieke kwaliteit er bestond tusschen een groot aantal A. Beerstraten en de voluit Anthonie Beerstraten gemerkte stukken. Men dacht er niet aan, dat er nog wel eens een tweede A. BeErstrateN kon bestaan hebben, te minder, omdat de Abraiam BeErstraten, dien men in de Archieven had gevonden, kuiper van zijn ambacht was. Toch is het bestaan van een schilder Abraham BEerstraten niet twijfelachtig meer, sinds ik voor cen tiental jaren op het landgoed Bowood van den Markies van Lansdowne een met diens naam on voornaam voluit gemerkt grezicht op het oude raadhuis te Kampen tcrug vond 2), Dit stuk bewijst niet alleen dat ABRAHAM BeERSTRATEN als schilder bestaan heeft, maar ook dat hij verreweg de beste schilder van de beide A. Beerstratens was. Aan hem moeten dus de goede, aan Antionie de zwakke, A. BeERstraten gemerkte stukken worden toegeschreven.

De Catalogus maalit cen zeer uitgebreid gebruik van het woord "Toegeschreven". $\mathrm{Nu}$ kan men zeggen ieder schilderij, dat Io. niet echt gemerkt is door den schilder; 20 . door geen andere uitwendige documenten en een onafgebroken traditie gestaafd wordt, is slechts "Toegeschreven". In dezen zin is bijv. het portret van ELISABETII BAS. slechts "toegeschreven" aan REMBRANDT en zijn de meeste werken van RUBENS van vaN DyCK en HALs slechts aan deze schilders "toegeschreven". Ook hij, die waarde hecht aan de resultaten van inwendige, d. w. z. niet van handteekeningen of documenten afhankelijke stijlkritiek kan

1) Zie bijv. Havard, l'Art et les Artistes hollandais in zijn artikel over Beerstrates.

2) WAAGEN, die het ook zag, wist met dehandteekening geen weg en noemde den meester BAUERSTADT Treasures of art, III 165 ). 
met deze uitdrukking vrede hebben, mits de beteekenis slechts duidelijk blijke en het gebruik uniform zij. Neemt men nu deze uitgebreide beteekenis van "Toegeschreven" aan, gelijk de catalogus in vele gevallen doet, dan mag dit woordje niet ontbreken bij No. 493 Clats van Beresteyn, Duinweg ${ }^{1}$ ). Immers niet alleen is het schilderij niet gemerkt en heeft het geen oude traditie achter zich (tot voor korten tijd heettc het RUISDAEL), maar er bestaat zelfs geen tweede schilderij van den meester, ja nog sterker, wij weten zelfs niet, of hij, behalve etser en teekenaar, ook schilder is geweest en zoo ja, welk vak hij als zoodanig beoefende.

Onze kennis beperkt zlch tot VAN DER WILLIGENS mededeeling, dat Claes VAN BERESTEYN 5 Jan. I $644^{2}$ ) leerling van SALOMON DE BRAX was en 4 Maart I684 begraven werd. VAN DER KELLEN (Peintre graveur blz. 24) schreef reeds in 1867-73: „Il se peut que VAN BERESTEYN ait aussi manié le pinceau; cependant nous n'avons jamais vu de tableau de ce maitrc, ni même rencontré son nom dans les catalogues de tableaux". Ook thans geldt nog hetzelfde: ik heb nooit eenig gemerlit schilderij van BERESTEYN gezien, noch ooit zijn naam in een ouden veilingscatalogus van schilderijen aangetroffen.

Om deze redenen schijnt het mij alleszins wenschelijk ons landschapje slechts op BERESTEYNS naam te plaatsen, voorzien van de noodige toelichting, dat n.l. de tocschrijving slechts berust op de overeenkomst van stijl met de etsen en teekeningen van den kunstenaar.

Bij No. 587, Hicr. Bosch, het snijden van de kei, valt op te merken, dat dit stukje thans algemeen en terecht als cen goede, oude copie wordt beschouwd. Inderdaad beantwoordt het niet in allen decle aan den hoogen maatstaf, dien men gerechtigd is aan de authentieke werken van den meester aan te leggen, die reeds tijdens en kort na zijn eigen leven zoo veelvuldig gecopiëerd werd.

Ik geloof niet dat er reden bestaat, om met den catalogus te veronderstellen dat het landschap van No. 13I2, vossenjacht door L. DE JONGII door JORIS

1) Ivenmin als bij No. I253 ROMEyn De Hooghe, Zinnebeeldige voorstelling van het Muntwezen, die hoegenaamd niet gelijkt op de gemerkte geschidderde behangsels in het stadhuis te Linkhuizen; bij No. $133^{6}$ A. KEY, portret van een aanzienlijk man, wiens gelijkenis met de authentieke werken in het museum te Antwerpen mij onvoldocnde schijnt om daaruit tot de identiteit van den maker te concludeeren; bij No. 1423 M. Laroon, vroolijk gezelschap, dat evengoed van Clates Pietersz. Quksix zou kunnen zijn; bij No, 183 I portret van Cornelis Nuyts op naam van Jurrian Ovens; bij No. 273 I op dien van J. v. Wijkersloo'r, en bij Nrs. $274^{6}$ en 2747 op naam van B. ZWAfindecroon. Deze beide laatste schilderijen zijn gemerkt met een monogram B. Z. dat thans algemeen, en willicht terecht, voor dat van ZWA ERDECRoon doorgaat. Het kan echter geen kwand er hier nogmaals - zie reeds O. H. I895. XIII, p. 47 - op te wijzen, dat wij voorloopig geen enkel bewijs, of bewijskrachtige aanduiding bezitten, datwerkelijk B. Z. = BenNard ZwaERdeckOON is.

2) De catalogus zegt, dat hij in dit jaar geboren werd. Er zijn echter reeds etsen met het jaartal I $6_{50}$ van hem bekend, v. d. K. Nis. $6-3$. 
VAN DER HAGEN zou geschilderd zijn. Wel lijkt de behandeling ervan zeer op dien meester, doch dit is een algemeene eigenschap van DE JONGHS kunst. Deze was mans genoeg om het zelf te doen, gelijk ik door tal van stukken zoude kunnen aantoonen. $\mathrm{Hij}$ is een nog te weinig geapprecieerd artist, aan wiens naam vooral zijn zwakste producten: de portretten veel af breuk hebben gedaan, terwijl zijn goede werken vaak aan meesters als A. CUvP, P. DE HooGH, Is. Ostade en HobBema worden toegeschreven en als zoodanig met groote sommen betaald.

No. 1523, OtTo Marseus, bosch met hagedissen enz. enz., heeft tot dusver als een echt, maar zwak werk van den meester kunnen gelden, hocwel de handteekening duidelijk op een anderen kunstenaar wijst. Is zij echt en is er niet in geknoeid, om er quasi een monogram van MARSEUS uit te maken, dan bevat zij de letters C. M. (V) I. S., waarvan de $v$ onzeker is en deze en de twee laatste letters wellicht in andere volgorde zijn te lezen. Sterker evenwel dan de apocriefe handteckening veroordeelt de zwakke en vluchtige schilderwijze het stuk. Men vergelijke het slechts met het zorgvuldig doorwerkte, soortgelijke tafereel in het Mauritshuis.

Bekijkt de aandachtige lezer op blz. I 77 de vier facsimiles van handteekeningen van den ouden F. v. MIERIS, dan valt terstond de afwijkende vorm vàn No. I6I3, Jacobs droom, in het oog. Naar het schilderij gaande is één oogopslag voldoende om de overtuiging te krijgen, dat ook dit niet alleen geen MIERIS, maar cen volkomen echte, zuivere en karakteristicke ARIE DE VOIS is, zoodat het geenerlei verwondering meer baart te lezen, dat het stukje nog I 2 April I8I3 in de veiling Hendrik Mullman (Cat. No, i76, teruggekocht voor $f$ i7o door MullmaN) onder dien naam is verkocht. Het kwam ook reeds onder den juisten naam voor in de verzameling van den Griffier FAGEL, waarvan de catalogus in het $2 \mathrm{e}$ deel van HOET is afgedrukt: Jacob slapende, door A. DE VOIS (blz. 409), maar toen deze collectic den 22 Mei I80I te Londen onder den hamer kwam, heette het merkwaardigerwijze (Buchanan, Memoirs of painting I 304) No. 4 I Francis Mieris - Jacob's Dream, 73/10/.-

$\mathrm{Bij}$ de vele verbeteringen, die de nicuwe catalogus ons brengt is een der minder gelukkige bestendigingen van bestaande onjuistheden ${ }^{1}$ ), de toeschrijving van No. 1656, de Hengelaar van CARel DE MoOR, aan diens zoon Carel ISAAK DE MOOR. Afgezien van de handteekening, die CAR̄. D. MOOR en niet C. I. DE MOOR of C. Moor C. F. Luidt, zooals alle, die mij van den zoon bekend zijn, wijst de schilderwijze duidelijk op den vader. Ter vergelijking haal ik hier een zijner meest bekende werken: Pyramus en Thisbe in de Pinakotheek te Turijn aan,

1) Jaarverslag I897, biz. I8. 
hetwelk reeds door Houbraken geprezen werd. Het vertoont in behandeling en coloriet de meest volslagen overeenkomst met het Amsterdamsche stuk.

Dit laatste is trouwens reeds door een van DE Moor's tijdgenooten, GERARD HOET, den Jonge, aan hem toegekend. Wij lezen in Dl. II van zijne bekende verzameling van veilingscatalogi blz. 456 :

Een jonge die hengelt, en een met een meisje die daar na zien, door den

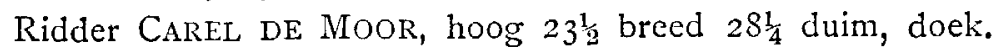

Het stuk waarvan de afmetingen precies met die van de Amsterdamsche vocrstelling overeenkomen, bevond zich toen (1752) in het cabinet van den bcwindhebber AdRIAAN LeONARD vaN Heteren te 's Gravenhage. Het is dus evenals ruim zestig andere stukken uit de verzameling van diens erfgenaam Jhr. Adriaan Leonard van Heterin Gevers, in 1809 in het Rijksmuseum gekomen.

DE MOOR schilderde hetzelfde onderwerp meermalen. In den veilingscatalogus Hendrik Verschudring, den Haag i7 Sept. I770, lezen wij onder No. 22 van den appendix:

Een Stukje, verbeeldende een Boere Jonge die met de Hengel zit te vissen, en waar na een Boere Meyd staat te zien, met verder bijwerk in een Landschap: zeer fraay geschildert door den Ridder KAREL DE MOOR; op paneel hoog $8 \frac{1}{6}$ breed Io duim.

Bij No. 1832 rijst de vraag, waarom J. Ovens juist de copiïst moet zijn van het portret van P. C. HoofT door SANDRART, evenals bij No. 799, waarom D. v. Tol juist den beroemden Dou van den Hertog van Westminster moet gecopieerd hebben.

Het tegenwoordig nummer I9I8, de Stroosnijder, stond, sedert het in I 808 in het Museum kwam, op naam van PAuLus, later op voetspoor van BoDE, Studiën, blz. I68, op dien van PIETER POTTER en wordt thans nog slechts aan dezen schilder toegeschreven. Ik geloof dat men veilig nog één stap verder kan gaan en het geheel aan hem ontnemen. Het vertoont eene geheel andcre kunstrichting en is wat teekening en modelleering aangaat verre boven de meestal zeer zwakke figuurtjes van PIETER POTTER verheven. Vooralsnog waag ik het evenwel niet, een bepaalden kunstenaarsnaam voor dien van POTTER in de plaats te stellen.

Hetzelfde geldt van No. 2267, Het eiland Onrust nabij Batavia, genaamd "Richting van A. STORCK". Het is ongeveer even ver uit de Richting van A. Storck als Batavia uit de richting van Amsterdam is.

Ook No. 2489, De prinsen van Oranje en graven van Nassau te paard, draagt een te gunstig etiquet, namelijk dat van ADRIAEN VAN DE VENNE. Van dezen schilder is slechts de compositie, gelijk wij weten door de prent van W. J. DELFF, bekend onder den naam van „Nassoviae Proceres”. Het origineel dezer 
prent, ongeveer even zoo groot, berust in het museum te Darmstadt en is een buitengewoon frisch, kleurig en geestig kunstwerkje. $\mathrm{Nu}$ is het mij onmogelijk aan te nemen, dat dezelfde artist deze saaie, indifferente, bijna levensgroote herhaling (al is die dan ook met wijzigingen) zou gemaakt hebben, vooral omdat mij nog minstens 4 of 5 anderen van ongeveer dezelfde kunstwaarde bekend zijn. Stond het aan mij, ik zoude het schilderij niet hooger dan „Copie naar" of "Atelier van A. V. VENNE" durven noemen.

Een gewaagde toeschrijving is ook die van het vrouwenportret No. 2730 aAN JAN VAN WIJKERSLOOT.

In de eerste plaats weten we nauwkeurig, hoe WijkERSLOOT portretten schilderde. Men vergelijke slechts de beide portretten der gebroeders VAN VELTHUYSEN in het stedelijk museum te Utrecht (Cat. 1904 Nrs. 3437 en 3438).

Voorts was WIJKERSLOOT een Utrechtsch schilder en is de voorgestelde dame, blijkens haar wapen, een lid van het Haagsche geslacht van PERsijn.

In de derde plaats komen andere portretten uit dezelfde familie en van denzelfden schilder voor, warop het monogram behalve I. W. nog een B, tegen de W. aan vertoont. De schilder heette dus I....W......., hetgeen niet past op JAN VAN WijCKERSLOOT, doch wel op den Hagenaar JAN JANSz. WESTERBAEN. Nu waren er evenwel twee schilders van dien naam, de eene in hoofdzaak bekend door de portretten van ARNOLDUS GEESTERANus en zijn vrouw '), waarvan het mansportret door het onderschrift van $\mathrm{H}$. BARY"S prent gedocumenteerd is, de ander door eenige weinige portretten met het monogram I W of I WB. De ecrste dragen een ouderwetscher karakter en zijn dus hoogstwaarschijnlijk het werk van den ouden JAN JANSz WesterbaEN ( \pm i600-i686), terwijl de gemonogrammeerde portretten dat van zijn gelijknamigen zoon zijn, die omstreeks $1 \sigma_{3} \mathrm{r} / 2$ geboren werd, leerling van zijn vader en ADR. HANNEMIAN was, onder G. Honthoksts invloed gerakkte en reeds voor 1672 stierf. In het Haagsche Gemeentemuseum bevindt zich onder No. 408 een J. I. WB f. 1655 gemerkt damesportret, dat evenals het Amsterdamsche schilderij, uit de familie VAN PERSIJN afkomstig is, al draagt het ook geen wapen. ${ }^{2}$ ) In het Haagsche Jaarboekje van 1893 heb ik over dit schilderij geschreven en ook op blz. 7 I op het Amsterdamsche stuk als het werk van den jongen J. J. Westerbaen gewezen. Ook in de veiling-Heeswijk van I9 Juni I900 was onder No. Io7 een gemonogrammeerde J. WESTERBAEN de Jonge, voorstellende het portret van een jongmensch, drickwart naar rechts, in een rood costuum, een vuurrooden mantel

1) Mauritshuis Nrs. 210, 2Ir.

2) Ik heb het persoonlijk bij de erfgenamen van een der laatste leden van dit gcslacht gekend. 
en een halsstrik van witte zijde. Zijn zwarte haren vallen over de schouders. De catalogus kende het monogram niet en schreef daarom het stuk aan den veel ouderen Hoornschen schilder JACOB WABEN toe. Eindelijk zag ik in I894 bij den pastoor VAN HeUkelum te Jutfaas een I. WB. gemonogrammeerd portret door dezen schilder.

Van een aantal door MOES in zijne Iconographia Batava vermelde portretten (Nrs. 395, 3747, 5977 en 753 I) durf ik hier vooralsnog niet te beslissen of zij van den ouden of den jongen WESTERBAEN zijn, evenmin als van een oude vrouw in een zwart kostuum en met een weduwckapje in een geschilderd ovaal, dat in het Museum te Caen (Cat. No. IO3) berust en wat wijze van monogrammeeren aangaat meer op den jongen en wat schildertrant betreft meer op cen ouden WesterbaEN trekt, terwijl het jaartal $1 \sigma_{49}$ ook beter op den vader dan op den toen 17 à I 8 jarigen zoon past.

Ook in buitenlandsche kunstveilingen trof $\mathrm{ik}$ af en toe werk van de Westerbaens aan. Zoo werd den 22 Juni 190 I te Londen onder den nam van SUSTERMANS het portret van een heer in een geelbruin wambuis met cen roode sjerp geveild, dat links boven het merk Ao $1 \sigma_{3} 8$ I.W. droeg. Eer ik dit ontdekte, dacht ik aan meesters als J. G. Cuyp of W. DE GEEST, vooral ondat het stuk krachtiger van kleur en van tegenstelling was dan het werk van den ouden WesterbaEN in het Mauritshuis, die wegens het jaarcijfer alleen in aanmerking; kan komen. Dit laatste geldt ook van het J.IV. I643 gemerkte mansportret der veiling vON DER ROPP te Keulen, November I S9o, dat HuGO DE GroOT hectte voor te stellen en aan J. V. WIJKERSLOOT werd toegeschreven, terwijl de beide pendants Nrs. 56 en 57 derzelfde veiling J. WB gemerkt, I66I gedateerd en van den jongen WESTERBAEN afkomstig waren.

Aan het slot van dezen' rondgang door het Rijksmuseum wagen wij ons thans nog in de afdeeling "Wapenschilderijen en teekeningen." Daar vinden wij onder No. 2988, de gekoppelde wapens der O. I. Compagnie met de handteekening J. BECX, de Jonge, fecit I65I. De catalogus kent dezen schilder blijkbaar niet; hij zegt slechts: Hollandsch schilder uit het midden der XVIIc eeuw. Toch is hij niet onvindbaar. Slaan wij de Middelburgsche gildeboeken op, dan vinden wij daarin (Obreens Archief VI, blz. I72 en vervolgens) eene geheele familie BECX en wel:

JERONIMUS BECKX, fijnschilder, onderteekent 8 Januari 1644 de gilderekening; desgelijks die over 1644,1651 , 1654 en 1655 , verliest in 1647 zijn vrouw en sterft zelf tusschen is October 1657 en 1658 .

JASPER BECKX, fijnschilder, sterft tusschen 25 Januari 1647 en 5 Januari 1649. 
120 KRITISCHE OPMERKINGEN OMTRENT OUD-HOLLANDSCHE SCHILDERIJEN ENZ.

Jeronimus Beckx, de Jonge, fijnschilder, komt 5 Januari 1649 en 30 November 1650 in 't gilde en betaalt als vrij meesterszoon slechts half entreegeld. JOIIANNES BeCkX onderteekent 18 October 1658 de gilderekening. Desgelijks I 5 Dec, I660, I Nov. I66r, 25 Oct. I662, 2 I Nor. I663 en 27 Sept. I669. Er staat bij hem nergens, welken tak van kunst hij uitoefende. Hij zou dezelfde kunnen zijn als de JAN BEX die den I9 Oct. I686 als vreemdeling en woonachtig te Delfshaven in het Delftsche gilde kwam (O. A. I, blz.92). Jeronimus Beckx, de Jonge, is vermocdelijk de vervaardiger van ons tafereel, terwijl van JASPER BECKX een meer groot dan fraai, voluitgemerkt stilleven verzeild is geraakt in het Pepergasthuis te Groningen, alwaar het in verwaarloosden toestand hangt en een zekeren ondergang tegemoet gaat. ${ }^{1}$ )

's-Gravenhage, Augustus Igo4.

(Wordt vervolgd.)

1) De verschillende BeCX'EN hebben recds tot een verward artikeltje in vov WURzBACH's pas verschenen Künstierlexicon aanleiding gegeven, waarin ons $165 \mathrm{I}$ gedatcerd stuk aan den 1647 gestorven JASPEK BeCX wordt toegeliend, die daarentegen wel in 1627 de schilder van het door J. SAnracon gegraveerd portret van SAM. SuAvius kan gewest zijn (MUller Nr. 52r4a.)

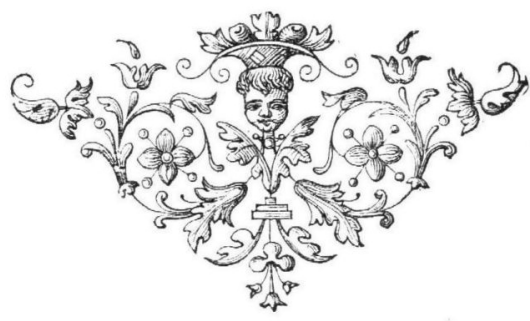

